\title{
Commentary: Valve-sparing reimplantation: Is support the key to aortic valve repair?
}

\author{
Gal Levy, MD, ${ }^{\mathrm{a}}$ Keshava Rajagopal, $\mathrm{MD}, \mathrm{PhD},{ }^{\mathrm{b}}$ and Abe DeAnda, Jr, $\mathrm{MD}^{\mathrm{a}}$
}

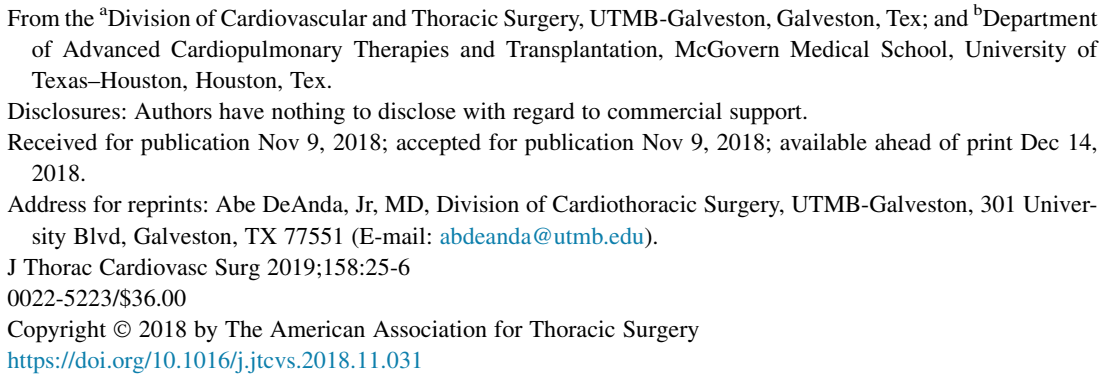

From the ${ }^{\mathrm{a}}$ Division of Cardiovascular and Thoracic Surgery, UTMB-Galveston, Galveston, Tex; and ${ }^{\mathrm{b}}$ Department of Advanced Cardiopulmonary Therapies and Transplantation, McGovern Medical School, University of Texas-Houston, Houston, Tex.

Disclosures: Authors have nothing to disclose with regard to commercial support.

Received for publication Nov 9, 2018; accepted for publication Nov 9, 2018; available ahead of print Dec 14, 2018.

Address for reprints: Abe DeAnda, Jr, MD, Division of Cardiothoracic Surgery, UTMB-Galveston, 301 University Blvd, Galveston, TX 77551 (E-mail: abdeanda@utmb.edu).

J Thorac Cardiovasc Surg 2019;158:25-6

$0022-5223 / \$ 36.00$

Copyright $(2018$ by The American Association for Thoracic Surgery

https://doi.org/10.1016/j.jtcvs.2018.11.031

The treatment for regurgitant aortic valve disease has progressed tremendously in the last 50 years, evolving from replacement, to repairing normal valves, to the possibility of repairing abnormal valves. Not surprisingly, this evolution followed the same trajectory as that of mitral valve repair and for some of the same reasons. Presumed or real advantages of a decrease in thromboembolic events, lower rates of endocarditis, and the avoidance of long-term anticoagulation all reinforce the preference of repair over replacement. Reardon ${ }^{1}$ highlighted the negative impact of valve replacement (vs repair) and referenced the seminal work of Carpentier ${ }^{2}$ with mitral valve repair to suggest the benefit of aortic valve repair. A lesson learned from Carpentier is the benefit of supporting the leaflet repair with a mitral ring or band. In this issue of the Journal, Mastrobuoni and colleagues ${ }^{3}$ demonstrate a similar finding when the aortic valve is repaired.

In this study from the Belgium group led by El Khoury, the results from 440 valve-sparing root replacements (VSRRs) were reviewed. ${ }^{3}$ The group was subdivided into 3 cohorts related to the traditional indications for VSRR: conventional for treatment of root aneurysms without aortic valve disease, debated for root aneurysms with aortic valve disease, and nonconventional for aortic valve disease when a root aneurysm is not involved. Their results demonstrated that independent of the status of the root and degree of aortic valve disease, VSRR could be performed safely and with excellent long-term durability. ${ }^{3}$ These results attest to the beauty of the VSRR, or the David procedure, and merit publication both for dissemination of the results as well as a tribute to the work of the El Khoury group and the vision of David and Feindel. ${ }^{4}$

Of interest are the 76 patients in the third, nonconventional group. They were younger (mean age, 42 years) and $68 \%$ had bicuspid aortic valves (BAVs). In part because of the presence of BAVs, 74 of the 76 patients required a cusp repair. The amount of repairs is not surprising in the

\section{References} 598-9. Surg. 2019;158:14-23.

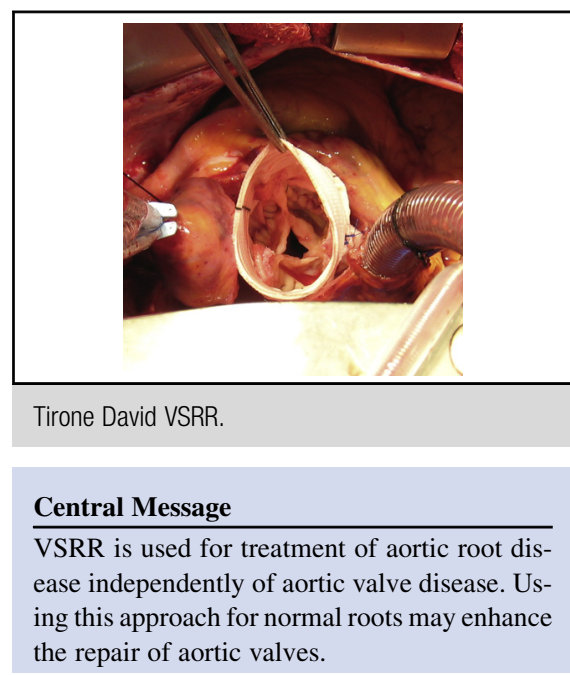

See Article page 14.

nonconventional group. By definition, the aortic valve disease in this group was secondary to leaflet pathology, which requires repairing or replacing the valve. The authors previously reported on the use of VSRR to increase the success of BAV repair, with a 6-year overall survival of $98 \%$ and freedom from reoperation and aortic valve disease greater than $2+$ of $100 \% .^{5}$ Thus, it is not surprising that in the "debated" group, in which of the 212 patients, 76 underwent BAV repair and 170 underwent cusp repair, the overall results were good and not limited to just BAV.

We can conjecture that any aortic valve repair benefits from the structural support provided by the artificial Dacron graft. This is not something stumbled upon. The authors are recognized for their detailed studies and understanding of the anatomy of the aortic valve and aortic root, and the role of support in aortic valve repairs. ${ }^{6,7}$ To successfully combine 2 procedures requiring expertise (ie, VSRR and aortic cusp repair) is a testament their experience. Of note, as Reardon ${ }^{1}$ remarks, the devil is in the details.

1. Reardon MJ. The devil is in the details. J Thorac Cardiovasc Surg. 2018;156:

2. Carpentier A. Cardiac valve surgery - the "French correction" J Thorac Cardiovasc Surg. 1983;86:323-37.

3. Mastrobuoni S, De Kerchove L, Navarra E, Watremez C, Vancraeynest D, Rubay J, et al. Long-term experience with valve-sparing reimplantation technique for the treatment of aortic aneurysm and aortic regurgitation. J Thorac Cardiovasc 
4. David TE, Feindel CM. An aortic valve-sparing operation for patients with aortic incompetence and aneurysm of the ascending aorta. J Thorac Cardiovasc Surg. 1992; 103:617-21

5. De Kerchove L, Boodhwani M, Glineur D, Vandyck M, Vanoverschelde JL, Noirhomme P, et al. Valve sparing-root replacement with the reimplantation technique to increase the durability of bicuspid aortic valve repair. J Thorac Cardiovasc Surg. 2011;142:1430-8.
6. De Kerchove L, Momeni M, Aphram G, Watremez C, Bollen X, Jashrai R, et al Free main length and coaptation surface area in normal tricuspid aortic valve: an anatomical study. Eur J Cardiothorac Surg. 2018;53:1040-8.

7. Nawaytou O, Mastrobuoni S, De Kerchove L, Baert J, Boodhwani M, El Khoury G. Deep circumferential annuloplasty as an adjunct to repair regurgitant bicuspid aortic valves with a dilated annulus. J Thorac Cardiovasc Surg. 2018; 156:590-7. 